Portland State University

PDXScholar

7-28-1995

\title{
The Role of Pulmocutaneous Baroreceptors in the Control of Lymphatic Heart Rate in the Toad Bufo Marinus
}

Dane Alan Crossley II

Portland State University

Follow this and additional works at: https://pdxscholar.library.pdx.edu/open_access_etds

Part of the Biology Commons

Let us know how access to this document benefits you.

\section{Recommended Citation}

Crossley II, Dane Alan, "The Role of Pulmocutaneous Baroreceptors in the Control of Lymphatic Heart Rate in the Toad Bufo Marinus" (1995). Dissertations and Theses. Paper 4892.

https://doi.org/10.15760/etd.6768

This Thesis is brought to you for free and open access. It has been accepted for inclusion in Dissertations and Theses by an authorized administrator of PDXScholar. Please contact us if we can make this document more accessible: pdxscholar@pdx.edu. 


\section{THESIS APPROVAL}

The abstract and thesis of Dane Alan Crossley II for the Master of Science in

Biology were presented on July 28,1995 , and accepted by the thesis committee and the department.

COMMITTEE APPROVALS:

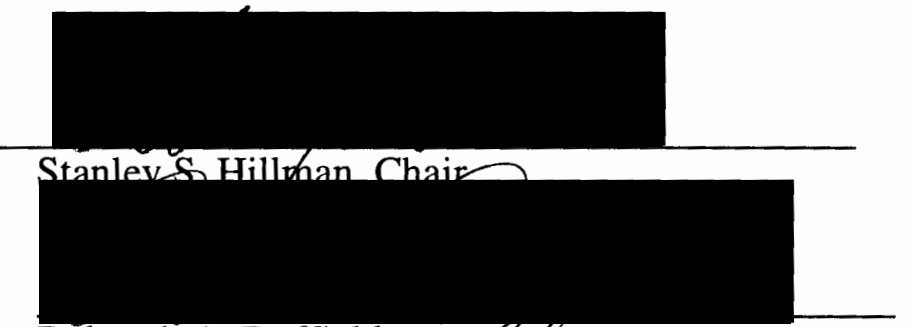

Deborah A. Duffield

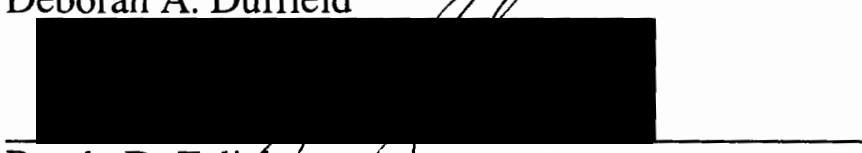

Randy D. Zelick ひ

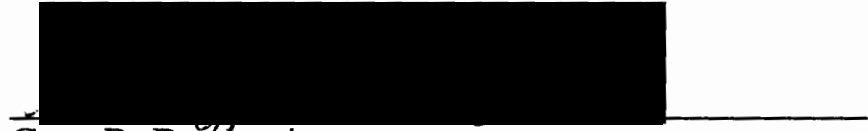

Gary R. Brodowicz

Representative of the Office of Graduate Stud ies

DEPARTMENT APPROVAL:

Leonard Simpson, Chair

Department of Biology

$* * * * * * * * * * * * * * * * * * * * * * * * * * * * * * * * * * * * * * * * * * * * * * * * * * * * * * * * * * * * * * * * * * * *$

\section{ACCEPTED FOR PORTLAND STATE UNIVERSITY BY THE LIBRARY}

by

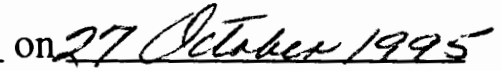




\begin{abstract}
An abstract of the thesis of Dane Alan Crossley II for the Master of Science in Biology presented July 28th, 1995.
\end{abstract}

Title: The role of pulmocutaneous baroreceptors in the control of lymphatic heart rate in the toad Bufo marinus.

The present study documents that baroreceptors located in the pulmocutaneous artery (PCA) are key components in control of lymph heart rate in amphibians. A negative feedback control loop exists between arterial pressure and lymphatic heart rate. The recurrent laryngeal nerve $(\mathrm{rLN})$, which innervates the PCA baroreceptors, transmits information on arterial pressure to integration centers in the central nervous system. Lymphatic heart rate (LHR) is reduced as a result of increases in arterial pressure. This loop was determined using three experimental protocols.

First, the correlation between LHR reduction and hormonally induced vasoconstriction was determined. Increases in arterial pressure due to pressor actions of angiotensin II and arginine vasotocin at high concentrations was negatively correlated to LHR.

Second, lymphatic heart rate changes due to natural increases in arterial pressure were compared to rate changes due to increase in arterial pressure after bilateral denervation of the rLN. Post-denervation LHR was not affected by natural 
increase in arterial pressure prior to the establishment of a new resting arterial pressure. Increase in arterial pressure due to administration of vasoconstricting hormones was negatively correlated with LHR following denervation.

Third, the effect on LHR due to direct stimulation of the rLN was studied. Stimulation of the rLN caused LHR to stop without increases in arterial pressure.

Presumably, this negative feedback loop is present to limit fluid return to the cardiovascular system from the lymphatic system during periods of acute hypertension. Reduction in the return of lymph volume to the cardiovascular system could eliminate potential damage to pulmonary tissues due to high arterial pressures. 
THE ROLE OF PULMOCUTANEOUS BARORECEPTORS IN THE CONTROL OF LYMPHATIC HEART RATE IN THE TOAD BUFO MARINUS

by

DANE ALAN CROSSLEY II

A thesis submitted in partial fulfillment of the

requirements for the degree of

\section{MASTER OF SCIENCE}

in

BIOLOGY

Portland State University

1995 


\section{ACKNOWLEDGMENTS}

I would like to acknowledge the people that have motivated me to continue when things became hard to deal with, these people are responsible for my development.

Stan Hillman for taking a rough edged individual into his lab and teaching him, among many other things, to be a biologist.

Debbie Duffield for adding to my development as a scientists and as a person.

My family for being supportive and tolerating me while I struggled through the last two years.

To Jesse Griggs for coming into my life and making me whole

Carey Crossley for returning to my life and listening when things were troubling.

To the committee for the effort you all gave on such short notice to read the thesis and for the excellent suggestions that were made.

To the frogs in what Mark now calls the swamp, thanks for the fun times and the intellectual conversation at the bullpen.

Ed DeGrauw for teaching how to do biology, Mark Bolke for the motivation and advice, and Jonn for helping when ever asked.

To all my brothers and friends for your unending friendship, and to Brady Coates to whom I dedicate my thesis, you will always be with me brother 


\section{TABLE OF CONTENTS}

\section{PAGE}

ACKNOWLEDGMENTS $\ldots \ldots \ldots \ldots \ldots \ldots \ldots \ldots \ldots \ldots \ldots \ldots \ldots \ldots \ldots$ iii

LIST OF TABLES $\ldots \ldots \ldots \ldots \ldots \ldots \ldots \ldots \ldots \ldots \ldots \ldots$

LIST OF FIGURES $\ldots \ldots \ldots \ldots \ldots \ldots \ldots \ldots \ldots \ldots \ldots \ldots \ldots \ldots \ldots$

INTRODUCTION $\ldots \ldots \ldots \ldots \ldots \ldots \ldots \ldots \ldots \ldots \ldots \ldots \ldots \ldots \ldots \ldots$

MATERIALS AND METHODS $\ldots \ldots \ldots \ldots \ldots \ldots \ldots \ldots \ldots \ldots \ldots$

Surgical procedures.......................... 14

Placement of nerve snares. . . . . . . . . . . . . . . . . 15

Implantation of electrodes. . . . . . . . . .

Study procedure............................... 15

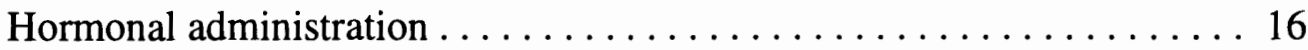

Denervation $\ldots \ldots \ldots \ldots \ldots \ldots \ldots \ldots \ldots \ldots \ldots \ldots \ldots \ldots \ldots \ldots \ldots, 16$

Neural stimulation. .......................... 17

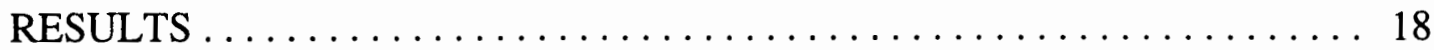

General effect of denervation $\ldots \ldots \ldots \ldots \ldots \ldots \ldots \ldots \ldots \ldots$

Effects of arginine vasotocin $\ldots \ldots \ldots \ldots \ldots \ldots \ldots \ldots \ldots \ldots \ldots$

Effects of increasing systolic pressure on LHR $\ldots \ldots \ldots \ldots \ldots \ldots 24$

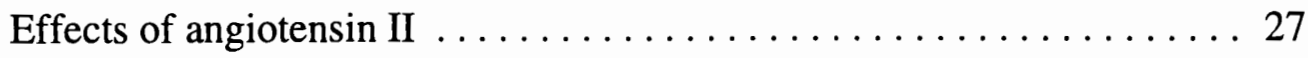

Effects of direct stimulation $\ldots \ldots \ldots \ldots \ldots \ldots \ldots \ldots \ldots .27$

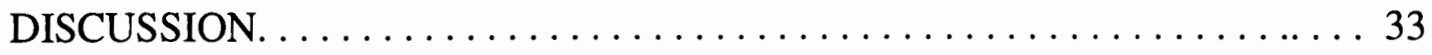

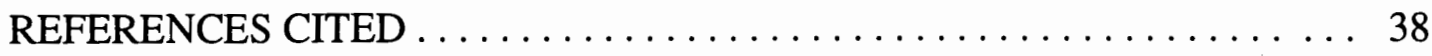




\section{LIST OF TABLES}

TABLE

PAGE

I Effects of recurrent laryngeal nerve denervation $\ldots \ldots \ldots \ldots 18$

II The correlation between lymph heart rate and change

in systolic pressure due to AVT $10-7 \mathrm{~g} / \mathrm{ml} \ldots \ldots \ldots . \quad 24$

III The correlation between increasing systolic blood pressure

and lymph heart rate due to AVT $10^{-6} \mathrm{~g} / \mathrm{ml} \ldots \ldots \ldots 25$ 


\section{LIST OF FIGURES}

FIGURE

PAGE

1. Effects of denervation on systolic arterial pressure $\ldots \ldots \ldots \ldots 20$

2. Mean LHR due to natural increase in arterial pressure before and after denervation. . . . . . . . . . . . 21

3. Mean systolic arterial pressure due to arginine vasotocin at increasing concentration

4. Mean LHR due to increasing concentrations of arginine vasotocin .

5. Control mean LHR and mean LHR due to increasing arterial pressure induced by arginine vasotocin before and after denervation 26

6. Effects of increasing concentrations of angiotensin II on mean systolic arterial pressure

7. Effects of increasing concentrations of angiotensin II on mean LHR

8. Control mean LHR and mean LHR due to increases

in arterial pressure induced by angiotensin II ...... 30

9. LHR 60 seconds before and during stimulation of the recurrent laryngeal nerve . 


\section{INTRODUCTION}

Development of highly water permeable skin and lymphatic hearts are important for blood volume control mechanisms in amphibians. Lymphatic hearts generally function to facilitate the movement of fluid from lymphatic vessels to the cardiovascular system. Considerable variance in the number of lymphatic hearts is found between the caecilian, urodele, and anuran amphibians. Caecilians have a bilateral pair of lymphatic hearts found in every body segment just under the skin, with several hundred pair possible in some animals. Caecilian lymph hearts receive lymph from short afferent channels connected to intersegmental lymphatics and move it into the intersegmental vein. Urodeles have intersegmental hearts located along the lateral line with the total number ranging from 8 to 23 bilateral pair. Lymph enters the urodele lymph heart from an intersegmental vessel and a branch of the lateral lymphatic vessel. Once lymph enters the hearts it is moved into the venous system at the vena lateralis. Adult anurans typically have two bilateral pair of lymphatic hearts, one anterior pair and one or two posterior pair. The anterior pair transfers lymph from an afferent vessel of the lateral lymphatics to the 3rd vertebral vein which empties into the internal jugular of the animal. Lymph movement in the caudal hearts involves entrance via ostia in the heart that allows movement from the dorsal lymph sac. Fluid then enters the vascular system via the posterior vertebral vein (Kampmeier 1920). The embryological development of lymphatics in amphibians has been thoroughly studied by Kampmeier (1969). Of particular interest is the development of anuran lymph hearts and the connections to the vessels mentioned previously. 
In larval anurans the modes of anterior and posterior lymph heart development are markedly different. For this reason it is important to examine the genesis of each structure individually. The anterior lymphatic hearts are the first lymphatic structures to develop in the toad embryo. These structures appear in animals $4 \mathrm{~mm}$ in length, located dorsal to the pronephros from what has been described by Kampmeier (1969) as a circumscribed plexus of channels. These channels form in conjunction with the 3rd and 4th intersegmental blood vessels between the myotomes and the growing skin. As the plexus changes, the surrounding mesenchymal cells congregate just outside the endothelium of the differentiating heart and will become the future contractile tissue (Kampmeier 1969). The evolving heart then separates from all connecting vessels with the exception of the 3rd intersegmental vein. As development continues the heart reestablishes a connection to afferent vessels from lymphatics with the additional establishment of valves in the heart. These valves are generated from expansions of endothelial tissue which then are divided to form the efferent and afferent valves (Kampmeier 1969). This process is not duplicated in the development of the posterior heart.

Posterior lymphatic hearts develop at the junction of the trunk and the tail of the tadpole at the point of hind limb bud (Kampmeier 1969). Emergence of the posterior lymph hearts occurs much later than anterior lymph hearts. Posterior lymph hearts have been noted in toad embryos of 10-12 mm length, appearing after the development of tail lymphatic vessels. At this size mesechymal cells congregate around a plexus of lymphatic vessels lateral to the vessel to become the posterior vertebral vein. With further progression the chamber of the heart is developed via the mergence and expansion of the lymph vessels initially surrounded by mesechymal tissue. Like its anterior counterpart, posterior lymphatic hearts make a transient break 
from the surrounding lymphatics, then establish a new connection with the enlarging lymphatic channel of the lateral line. In addition, the efferent connection is made to the posterior vertebral vein with the subsequent valves developing as well. In summarizing the difference in the development, the anterior pair of hearts develop from blood vessels while the posterior pair develops from established lymphatic vessels. Given these differences the morphological similarities are deserving of analysis.

The posterior and anterior hearts are morphologically similar in anuran amphibians. The anterior hearts are located under each scapula, resting on the transverse process of the third vertebra (Muller 1834; Panizza 1833) and are covered by the serratus medialis muscle (Kampmeier 1969). Each anterior lymph heart receives lymphatic fluid from subscapular lymph sinuses via several valvular openings in the heart (Radwanska 1906). The hearts then empties into the anterior vertebral vein which unites with the internal jugular vein. The posterior lymphatic heart is located more superficial than the anterior heart. Posterior lymph hearts are located on each side of the urostyle, lying in the angle created by the fusion point of the ileum and the base of the urostyle. Each posterior lymph heart has three points of attachment, one medial to the urostyle, one cranial to the ileum, and one caudolateral to the musculature of the thigh (Obara 1962). A number of lymph sinuses communicate with each heart via small valve-like pores in the heart (Kampmeier 1969). Lymphatic fluid is then shunted into the vascular system via posterior vertebral veins which in turn connect to the iliac vein. In anurans, the anterior and posterior lymphatic hearts are structurally similar to each other.

Posterior and anterior lymphatic hearts are both comprised of three tissue layers. An adventiva, constructed of elastic and connective tissue, sheaths each heart. 
The tunica media, which is the muscular coat, is composed of skeletal muscle fibers of varying length and thickness (Kampmeier 1969). The structure of this tissue is similar to that of cardiac muscle, with intercalated disks and muscular trabeculae as noted by Ranvier (1890). Each chamber is lined with a typical tunica intima, consisting of endothelial tissue in a zig-zag pattern (Ranvier 1890). The size of the anterior and posterior lymphatic hearts has considerable variance among various species.

Lymphatic heart size differs between various species of anuran amphibians. In Breviceps verrucosus that measures $38 \mathrm{~mm}$ snout to vent in length, each posterior lymphatic heart measures $11 \mathrm{~mm}$ (Beddard 1908). This tremendous size is emphasized when compared with the posterior lymph heart length of $6 \mathrm{~mm}$ in the much larger anuran, Rana guppyi (Kampmeier 1969). Clearly the difference in size could have implications for the output of the hearts in these species. However, difference in size fails to translate into variation in innervation of the organ.

Anuran amphibians have a series of peripheral neural connections to each lymphatic heart. Each posterior lymph heart is innervated by two branches of the XIth spinal nerve and a branch of the IXth and Xth spinal nerves (Obara 1961). Each anterior heart is innervated by a branch of the second spinal nerve (Priestley 1878). These hearts have been shown to be under the control of higher centers located above the atlantooccipital articulation (Priestley 1878). The role of these centers as inhibitors of rhythmic heart contraction is exemplified in characteristics of lymphatic heart function.

Paired lymphatic hearts fail to demonstrate synchronized contraction in either the posterior or anterior pair of hearts. Contraction can vary in both pair of hearts with loss of contraction for periods of 1 to 2 min being induced by disturbance of an animal (Priestley 1878). This irregularity in contractile rate can be ascribed to the central 
nervous system (CNS) having inhibitory effects on rhythm of lymphatic heart contraction (Kampmeier 1969). Skeletal muscle of lymph hearts is inhibited by a reduction of motor stimulation to the hearts. Variation in rhythm can induce changes in the pressures generated during the contraction of the heart, and volume of fluid moved over time.

Each heart is capable of generating pressures of $2.0 \mathrm{kPa}$ (Jones et al. 1992), with negative pressure values achieved as well (DeGrauw unpublished data). Rate of lymph heart contraction in Bufo marinus in a normal hydrated state ranges from 48 to 56 beats per minute (Jones et al. 1992; Parsons et al. 1993), while animals in a dehydrated state exhibit rates of 31 beats per minute (Jones et al. 1992). Lymphatic fluid is moved, via the lymphatic hearts, from the lymphatic sacs found throughout the subcutaneous space to the cardiovascular system of the animal. Alterations in rate of heart contraction result directly in changing the amount of lymphatic fluid that enters the cardiovascular system of anuran amphibians, influencing blood volume.

Amphibians, unlike other terrestrial vertebrates, must maintain blood volume under conditions of high evaporative water loss. Fluid loss in amphibians is equivalent to the losses of a free surface of water. Thus they have greater potential to suffer dehydrational stress than other vertebrates. Dehydration can induce reduction in cardiac output in Bufo marinus and Rana catesbeiana primarily as a result of a decrease in pulse volume (Hillman 1987). In order to reduce the effects of dehydration, amphibians have mechanisms in addition to those found in other vertebrates.

Transcapillary reabsorption of fluid in amphibians is a potential mechanism to reduce effects of dehydration on the cardiovascular system. Vertebrates maintain capillary fluid balance if the transcapillary hydrostatic pressure is equal to the colloid 
osmotic pressure (Withers 1992). Transcapillary hydrostatic pressure is a result of pressure generated in the capillary due to the heart and interstitial hydrostatic pressure. Colloid osmotic pressure is primarily due to plasma proteins within the capillary. Changes in the magnitude of these forces result in variation of the amounts of plasma filtered or reabsorbed at the capillaries. At rest, hydrated Bufo marinus and Rana catesbeiana each exhibit a net ultrafiltration, or net movement of fluid to the interstitial space (Hillman, Zygmunt and Baustian 1986). At water loss states of greater than $22 \%$ of body mass in Bufo marinus reabsorptive forces begin to dominate; however, Rana catesbeiana continues with net ultrafiltration (Hillman, Zygmunt and Baustian 1986). At volume losses of less than $22 \%$ body mass this mechanism would not mobilize fluid, though Bufo marinus does maintain blood volume (Hillman, Zygmunt and Baustian 1986). These data indicate that Starling forces are not involved in maintaining a relatively constant blood volume.

Permeability of the skin to water enables amphibians to use transcutaneous fluid flux as a mechanism to maintain blood volume. Although the correlation of skin permeability with degree of terrestriality has been examined the significance has been questioned. Studies comparing a terrestrial species and an aquatic species has indicated that a correlation exist between permeability of the skin and terrestriality (Mullen and Alavardo 1976). However, other studies have shown that no correlation exists between the two variables thus a definitive statement cannot be made. There are considerable differences found interspecifically in variance of hydraulic conductivity, or permeability, of the skin due to loss of body water (Shoemaker and Nagy 1977). A change in permeability of the skin is facilitated by increasing arginine vasotocin (AVT) concentrations in the blood, induced by the escalating body fluid concentration (Bentley 1974). Clearly cutaneous flux of water via osmosis has potential for impact 
on blood volume, but the extent of the effect has been questioned. Wentzell, Mcneil, and Toews (1994) found that some if not most water taken up via transcutaneous absorption enters the lymphatic space before entering the cardiovascular system. This limits the role of direct flux of water into cutaneous capillaries. Additional research on the flux of sodium ions has shown 50 percent of the sodium and subsequent water uptake enters the lymphatic space, and 50 percent enters the capillaries directly (Talbot 1993). Exact pathways that fluid absorbed across the skin travels to get to the cardiovascular system is unclear.

Absorption of fluid from the bladder in amphibians acts as an additional source of water to maintain blood volume. The bladder of amphibians is a distensible outpocketing of the cloaca which varies in size with the degree of terrestriality of the animal. The walls of the anuran amphibian bladder possess a highly developed vasculature in addition to a highly distensible wall. Anuran amphibians bladder volumes range from 1 to 50 percent of the animal's body mass (Shoemaker and Nagy 1977 ), with a wall that is variably permeable to water. The degree to which the bladder is permeable is determined by the hydration state of the animal. As an anuran dehydrates, AVT concentration in the blood increases. The rising concentration of AVT increases the permeability of the wall of the bladder to water, thus allowing maintenance of blood volume (Shoemaker and Nagy 1977). Bufonids have been shown to maintain blood volume when subjected to dehydrational stress until bladder reserves were eliminated (Ruibal 1962; Shoemaker 1964). The bladder allows amphibians to forage longer in a terrestrial environment using the bladder reserves as a supplementary source of water. The fluid reabsorbed from the bladder can travel one of two paths into the cardiovascular system. Bladder water can be absorbed directly into the capillary network in the bladder wall or into the interstitial spaces and into the 
lymphatic system. These potential routes of fluid absorption are similar to those found in the skin, however the role of either path in transbladder absorption is unclear.

Two other mechanisms are available to anuran amphibians to maintain blood volume: nephrostomal and lymphatic movement. Nephrostomes, or peritoneal funnels, are a mechanism unique to amphibians and are located on the surface of the kidney with an opening into the body cavity. Each funnel is ciliated and involved in movement of fluid from the body cavity into the cardiovascular system (Rugh 1938). Each funnel is functionally responsive to AVT, increasing the rate at which cilia beat in response to escalating levels of AVT (Morris 1981). The renal vasculature is the point at which peritoneal funnels return fluid to the cardiovascular system (Morris 1981), thus acting as a route to move fluid reserves from the body cavity to maintain blood volume. Movement of fluid has previously been illustrated by Rugh (1938) and Morris (1981) via placement of ink in the body cavity and observing passage into the renal vasculature. Further studies conducted by Morris (1981) indicated that pressures generated by the peritoneal funnels were insufficient to overcome the pressure in the renal vascular system. For this reason the role of the peritoneal funnels in the regulation of blood volume is unclear.

The function of lymphatics and lymph hearts in maintenance of blood volume is clearer. Lymphatic systems in anuran amphibians function to transport interstitial fluid from the extracellular spaces to the cardiovascular system. Fluid lost through ultrafiltration in capillary beds is returned via lymphatic vessels to the cardiovascular system. The lymphatic system also acts in the transportation of fluid absorbed transcutaneously from lymphatic sacs located throughout the body to the cardiovascular system. Lymphatic hearts are of particular importance to anuran amphibians blood volume control due to their role in circulation of fluid. Lymphatic 
hearts are capable of returning fluid from the interstitial space to the cardiovascular system at reported rates of $1 \mathrm{ml} / \mathrm{min}$ (Parsons et al 1993) or $2 \mathrm{ml} / \mathrm{min}$ for a $\mathrm{kg}$ animal (Baustian 1988). In a $\mathrm{kg}$ animal with $73 \mathrm{ml}$ of plasma these rates are 2.7 percent of plasma volume returned per minute. Given this fluid return rate there exists a significant mechanism to increase blood volume, thus increasing arterial blood pressure in a short periods of time. Various studies that eliminated the anterior and posterior lymphatic hearts illustrated the importance of lymphatic hearts.

Electrocautery ablation of the hearts induces a fall in the blood plasma levels from a calculated 55 percent of the blood volume to 15 percent (Zwemer and Foglia 1943). Additionally, destruction of lymphatic hearts induces hemoconcentration and failure to return to normal blood volume following hemorrhagic stress in Bufo marinus (Baustian 1988). The importance of lymphatic heart function in amphibians is emphasized by high mortality in many animals within 4 days of lymphatic heart destruction (Baustian 1988) and (Zwemer and Foglia1943).

The importance of lymphatic function is additionally illustrated by amphibians undergoing dehydrational stress. Dehydration tolerance in amphibians varies with the degree of terrestriality the animal exhibits. The ability to maintain plasma volume differs between Bufo marinus, a terrestrial species, and Xenopus, an aquatic species, under dehydrational stress (Hillman 1978). Terrestrial species have greater ability to maintain blood volume than aquatic species. An additional illustration of aquatic and terrestrial differences is the change in hematocrit in Rana catesbeiana during dehydration and its maintenance in Bufo marinus until water losses of 20 percent of body mass (Hillman, Zygmunt, and Baustian 1986). Maintenance of constant hematocrit was possible without transbladder, transcapillary, or transcutaneous flux of water in Bufo marinus (Hillman, Zygmunt, and Baustian 1986). The elimination of 
these three potential routes of blood volume control leaves ciliated peritoneal funnels and lymphatics to regulate blood volume. Eliminating peritoneal funnel activity is difficult; however, lymphatic activity, particularly the lymph hearts, have been successfully eliminated from the regulation loop as stated. The importance of lymphatic hearts in regulation of blood volume is illustrated by the loss of regulation of blood volume once lymphatic hearts are eliminated. Given the importance of lymphatic hearts it is imperative to understand the control mechanisms of lymph heart activity. Arterial baroreceptors may be one such mechanism.

Baroreceptors are found in one of three locations in the amphibian circulatory system. Ishii and Ishii (1978) found the receptive fields of these baroreceptors are located midway on the pulmocutaneous trunk located between the truncus and the point of division of the pulmonary and cutaneous arteries in Bufo vulgaris. The receptive fields in Bufo marinus were found to be located in the pulmocutaneous artery (PCA) or at the point in the truncus that gives rise to the PCA (Van Vliet and West 1987). A second set of baroreceptors have been identified in the aortic trunk innervated by the aortic nerve which is a branch of the pharyngeal nerve (Ishii, Ishii and Kusakabe 1985). A third set of baroreceptors have been isolated in the carotid labyrinth, an expanded chamber at the base of the internal carotid arteries, first identified by Neil, Strom and Zotterman (1950) and subsequently clarified by Ishii, Honda, and Ishii (1966). These structures are an integral component of blood volume control.

Blood volume changes can influence blood pressure. As blood volume rises, cardiac output increases, which increases arterial pressure. The high arterial pressure causes the loss of fluid volume at the kidney and return of blood volume to normal (Guyton 1991). A decrease in blood volume will reduce cardiac output, and decrease 
arterial pressure. This again affects the kidneys, causing less fluid to be lost and a return to normal blood volume (Guyton 1991). A variety of mechanisms are also used to detect and regulate changes in arterial blood pressure. Of these, the rapid acting components are baroreceptors. Baroreceptors are nerve endings located in the walls of arteries and are stimulated by alterations in the degree of stretch in the wall. Distention of the arterial wall increases the rate of discharge from the baroreceptors. The stimulation of baroreceptors induces vasodilation of peripheral vasculature, decreases heart rate, and decreases force of cardiac contraction. These mechanisms fail to be effective in cases of chronic elevation of pressures and are strictly functional in cases of acute changes. Baroreceptors are concentrated in large arteries such as the aortic arch and the carotid artery of vertebrates. Amphibian baroreceptors have been illustrated as a mechanism to monitor arterial pressure changes (Van Vliet and West 1986). One site is located in the walls of the pulmocutaneous trunk (PCA) (Neil, Strom, and Zotterman 1950). Distention of the vascularly isolated PCA decreases arterial blood pressure and heart rate in Bufo marinus, indicating that feedback from the pulmocutaneous baroreceptors can regulate blood pressure (West and Van Vliet 1983; Ishii and Ishii 1978; Hoffman and Cordeiro de Sousa 1982). Additional research involving direct stimulation of the recurrent laryngeal nerve (rLN) induced a similar baroreflex to that of vascular distention indicating the role of the rLN in cardiovascular control (West and Van Vliet 1983; Van Vliet and West 1986; Ishii and Ishii 1978; Hoffman and Cordeiro de Sousa 1982). The recurrent laryngeal nerve has afferent fibers from baroreceptors located in the wall of the pulmocutaneous artery (Ishii and Ishii 1978), as well as, laryngeal mechanoreceptors (Van Vliet and West 1986). Direct measurement of discharge frequency in the rLN, with increases in arterial pressure, also indicates the role of PCA baroreceptors in control of 
cardiovascular function (Ishii and Ishii 1978; Van Vliet and West 1987). PCA baroreceptors are the primary sensors of arterial pressure since they respond to pressure changes in a normal physiologic range (Feder and Burggren 1992). The aortic arch baroreceptors were isolated by Ishii, Ishii, and Kusakabe (1985), but their function is unclear due to the lack of response to direct electrical stimulation or distention of the aortic branches. Baroreceptors located in the carotid labyrinth were originally suggested to control cardiovascular function (Meyer 1927). However, a baroreflex was only induced at pressures of $70 \mathrm{mmHg}$, which is outside the physiological range (Ishii, Honda, and Ishii 1966) The rational for PCA being the principal feedback mechanism of arterial blood pressure variation in anurans is simply explained. Amphibian cardiovascular systems are adapted in a manner that places the pulmonary circuit and the systemic circuit in parallel (Feder and Burggren 1992). Amphibian pulmonary microvasculature fails to be protected by a low pressure pulmonary circuit, such as that found in endotherms, making the lungs potential areas of damage. PCA baroreceptors could initiate a reduction in arterial pressure and heart rate as pressure become critical to pulmonary vasculature. Increases in pulmonary resistance due to electrical stimulation of the $\mathrm{rLN}$, in concert with reduction of peripheral resistance (Van Vliet and West 1986), reduces arterial pressure within the pulmonary circuit via a bypass to the cutaneous system defending these tissues. Additionally, increases in filtration across the pulmonary vasculature induced by denervation of the rLN (Smits, West, and Burggren 1986), further pronounce the importance of PCA baroreceptors role as a protective mechanism of the vasculature of the lungs. Given the primary role of PCA baroreceptors in blood pressure regulation, an important additional structure to control would be the lymphatic hearts. 
Due to the importance of lymphatic hearts in control of blood volume and the role of baroreceptors on arterial pressure, the role of baroreceptor control of lymphatic heart function must be understood. The hypothesis of this study is that a negative feedback loop exists between arterial pressure in the PCA and lymphatic heart rate. If this feedback loop is present, then increases in arterial pressure should decrease lymphatic heart rate. Three experimental protocols were used to test this hypothesis. First, hormones were administered to increase arterial pressure. Arginine vasotocin and angiotensin $\Pi$ are both vasopressors at high concentrations and were used to increase arterial pressure which should decrease lymph heart rate. Second, the recurrent laryngeal nerve was cut, with hormones infused before and after ablation. Denervation of the rLN should eliminate any decrease in lymph heart rate do to increasing arterial pressure. Finally, the recurrent laryngeal nerve was directly stimulated, which should stop lymph heart contraction if the hypothesis is correct. 


\section{METHODS AND MATERIALS}

Animals

Experiments were performed on 35 toads (Bufo marinus) in a resting state. The animals were obtained from Charles Sullivan Co. and varied in mass from 115 grams to 835 grams. Animals were housed in slanted tubs, allowing access to both water and dry areas, until surgery.

\section{Surgical procedures}

Animals were anesthetized via immersion in a solution of tricaine methane sulfonate (MS 222). Skin and muscle layers were cut distal to the parotid gland of each animal along the left side allowing access to the body cavity. Occlusive cannulation of the left systemic arch was conducted via the procedures used by Hillman (1987) using a PE 90 cannulae. Skin and muscle layers were then separately sutured closed. Additionally, the ventral abdominal vein was occlusively cannulated posteriorly with PE 90 . This procedure was followed by isolation of the recurrent laryngeal nerve which innervates the pulmocutaneous trunk of the animal (see below).

One posterior lymphatic heart was isolated and cannulated using PE 10 tubing via procedures used by Jones, Wentzell, and Toews (1992). The skin was sutured closed and the cannula was anchored to the dorsal surface. To prevent fluid loss the cannula was occluded with a copper wire plug until the trial period. Prior to any study each animal was given 12 hours postoperative rest. 
Placement of nerve snares

The recurrent laryngeal nerve was accessed bilaterally via the procedures used by Van Vliet and West (1985). This allowed the placement of a loop of monofilament thread around each nerve anterior to the baroreceptors located in the pulmocutaneous trunk. This filament was externalized and the incision was then sutured closed.

\section{Implantation of stimulating electrodes.}

Neural stimulators were implanted in 7 animals of various sizes. Access to the recurrent laryngeal nerve was accomplished in an identical manner used in nerve snare placement. An intact nerve was isolated unilaterally and cleared of connective tissue above the pulmocutaneous artery. Once the nerve was isolated and cleared, two silver wires were wrapped around the nerve and tightened to ensure contact. Each wire was then anchored to the body wall musculature and soldered to the insulated wire. Each wire was anchored to the dorsal surface of the animal to reduce chance of removal.

\section{Study procedure}

Pressure was measured by connecting arterial and lymphatic cannulas to pressure transducers. The transducers were connected to a NARCO Bio Systems physiograph with the arterial cannula connected to a strain gage coupler and lymphatic pressure connected to a universal coupler. Both systems were calibrated using the ventral surface of the animal as zero centimeters of water pressure. To calibrate the system the tip of the cannula to be connected to the arterial cannula was increased in height by increments of $10 \mathrm{~cm}$ to simulate increasing pressure on the transducer. Test 
animals were placed in a covered tub with water and given an acclimation period of an unspecified time to allow blood pressure to become constant. This was followed by the experimental treatment.

Hormonal administration

Arginine vasotocin (AVT) was diluted in $0.8 \% \mathrm{NaCl}$ to concentrations from $10^{-12} \mathrm{~g} / \mathrm{ml}$ to $10^{-6} \mathrm{~g} / \mathrm{ml}$ was administered to 14 animals. Each administration consisted of $0.5 \mathrm{ml}$ of AVT solution followed by a flush of $0.1 \mathrm{ml}$ of $0.8 \% \mathrm{NaCl}$. Before each infusion the animal was allowed to return to the baseline arterial pressure which was determined at the onset of the study. If the infusion failed to elicit a response, a period of at least $5 \mathrm{~min}$ was allowed before the next infusion.

Angiotensin II (ANG II) was also used at concentrations of $10^{-10} \mathrm{~g} / \mathrm{ml}$ to $10^{-4}$ $\mathrm{g} / \mathrm{ml}$. The methods for infusion of ANG II followed those of AVT.

\section{Denervation}

AVT was administered in dosages of $10^{-7} \mathrm{~g} / \mathrm{ml}$ and $10^{-6} \mathrm{~g} / \mathrm{ml}$, with the effects on systemic blood pressure and lymphatic heart rate measured in 13 different toads. Each dosage was followed by a rest period allowing the pressure to return to resting conditions. During the denervation procedures the nerve snares were pulled out of the animal cutting the recurrent laryngeal nerve. The animal was given an acclimation time frame which was determined to be the point at which the systemic blood pressure remained at a constant level. The animal was then infused with a second administration of AVT and the effects on the arterial pressure were recorded. 
Neural stimulation

Wires were connected to a Grass model S4 stimulator with voltage used during the study at a frequency of $10 \mathrm{~Hz}$. Direct stimulation of the recurrent laryngeal nerve was conducted with pulses of stimulation voltage of 0.5 volts to 7.0 volts with increases of from 0.2 volts to 1.0 volt between each stimulation. Each stimulation was executed with biphasic continuous pulses, each pulse with a duration of 1 millisecond with 1 millisecond between pulses. Time frame of stimulus application varied from 5 $\mathrm{sec}$ to $45 \mathrm{sec}$. Effects on lymphatic heart rate and mean systemic blood pressure were recorded during each stimulation. A rest of 5 minutes minimum was given the animal between each stimulation.

Animals that developed difficulties during the execution of the study were excluded. Particularly the inability to record systolic blood pressure or lymphatic heart pressure and rate were reasons to eliminate an animal from the study.

\section{Statistical analysis}

Repeated measure multivariate analysis of variance (MANOVA) was used to determine the effects of treatments on blood pressure and lymphatic heart rate. Correlation's were calculated using simple linear regression. A probability level of $p<$ .05 was used to identify statistical significance for all tests. Macintosh statistical program Statistica was used in the analysis. 


\section{RESULTS}

\section{General effects of denervation}

Bilateral denervation of the rLN induced a rise in arterial blood pressure with periodic sinusoidal wave patterns developing in the recorded pressure. Peak systolic pressure continued to rise to a maximum in all animals, at which point pressure decreased to a resting pressure above that of the original systolic pressure predenervation. Lymphatic heart rate post denervation decreased to zero in all animals due to a fright response caused by handling. Lymph heart contractions returned after a variable time frame while the systolic pressure continued to rise.

TABLE I

EFFECTS OF RECURRENT LARYNGEAL NERVE DENERVATION

\begin{tabular}{ccccccc} 
TOAD & RSP & \multicolumn{1}{c}{ PSP } & tPSP & NRSP & tNRSP & tLH \\
19 & $82 \mathrm{~cm}$ & $120 \mathrm{~cm}$ & $7 \mathrm{~min}$ & $90 \mathrm{~cm}$ & $28 \mathrm{~min}$ & $1.0 \mathrm{~min}$ \\
21 & $52 \mathrm{~cm}$ & $100 \mathrm{~cm}$ & $9 \mathrm{~min}$ & $65 \mathrm{~cm}$ & $29 \mathrm{~min}$ & $5.0 \mathrm{~min}$ \\
25 & $48 \mathrm{~cm}$ & $83 \mathrm{~cm}$ & $8 \mathrm{~min}$ & $54 \mathrm{~cm}$ & $24 \mathrm{~min}$ & $1.5 \mathrm{~min}$ \\
26 & $60 \mathrm{~cm}$ & $86 \mathrm{~cm}$ & $18 \mathrm{~min}$ & $68 \mathrm{~cm}$ & $63 \mathrm{~min}$ & $4.0 \mathrm{~min}$ \\
27 & $50 \mathrm{~cm}$ & $93 \mathrm{~cm}$ & $11 \mathrm{~min}$ & $64 \mathrm{~cm}$ & $46 \mathrm{~min}$ & $8.5 \mathrm{~min}$ \\
$\mathrm{X} ;$ SE & $58.5 ; 6.2$ & $96.4 ; 6.6$ & $10.6 ; 2.0$ & $68.2 ; 5.9$ & $38.0 ; 7$ & $4.0 ; 1.4$
\end{tabular}

Table 1 illustrates the pre-denervation resting systolic pressure (RSP), peak systolic pressure achieved (PSP), time frame to reach a peak systolic pressure (tPSP), 
new resting systolic pressure (NRSP), time elapsed post-denervation before the establishment of a new resting systolic pressure (tNRSP), and time elapsed when lymphatic hearts began contractions (tLH).

Systolic pressure increased in all animals post-denervation over time (igure 1). An analysis of lymphatic heart rates over four categories of increasing systolic pressure, pre-denervation and post-denervation, indicated an effect of the denervation event on lymphatic heart rate (Figure 2). A decrease in mean resting lymph heart rate was observed during increasing systolic pressure prior to denervation. Once denervation was completed, resting mean lymphatic heart rate failed to vary with change in systolic pressure. Post-denervation lymphatic heart rates and systolic blood pressures were collected prior to the establishment of a new resting systolic pressure. The lymphatic heart rate response to increasing systolic blood pressure was significantly affected by bilateral denervation of the $\operatorname{rLN}(\mathrm{p}<.05)$.

Effects of arginine vasotocin on systolic pressure and LHR.

There was a significant difference in effect $(\mathrm{p}<.05)$ on systolic blood pressure due to administration of AVT at concentrations $10^{-7} \mathrm{~g} / \mathrm{ml}$ and $10^{-6} \mathrm{~g} / \mathrm{ml}$ when compared to treatments of $10^{-12}$ to $10^{-8} \mathrm{~g} / \mathrm{ml}$ and control values (Figure 3 ). AVT of concentrations $10^{-7} \mathrm{gm}$ and $10^{-6} \mathrm{gm}$ induced an increase in systolic pressure in all test animals. AVT of the concentrations $10^{-7} \mathrm{~g} / \mathrm{ml}$ and $10^{-6} \mathrm{~g} / \mathrm{ml}$ also reduced lymphatic heart rate which was significantly different $(\mathrm{p}<.05)$ from either control values or other concentrations (Figure 4). Administration of AVT of concentrations $10^{-7} \mathrm{~g} / \mathrm{ml}$ and $10^{-6} \mathrm{~g} / \mathrm{ml}$ reduced the rate of lymphatic heart contraction (Figure 4). Effects of hormone concentration on systolic blood pressure were found to be uncorrelated to 


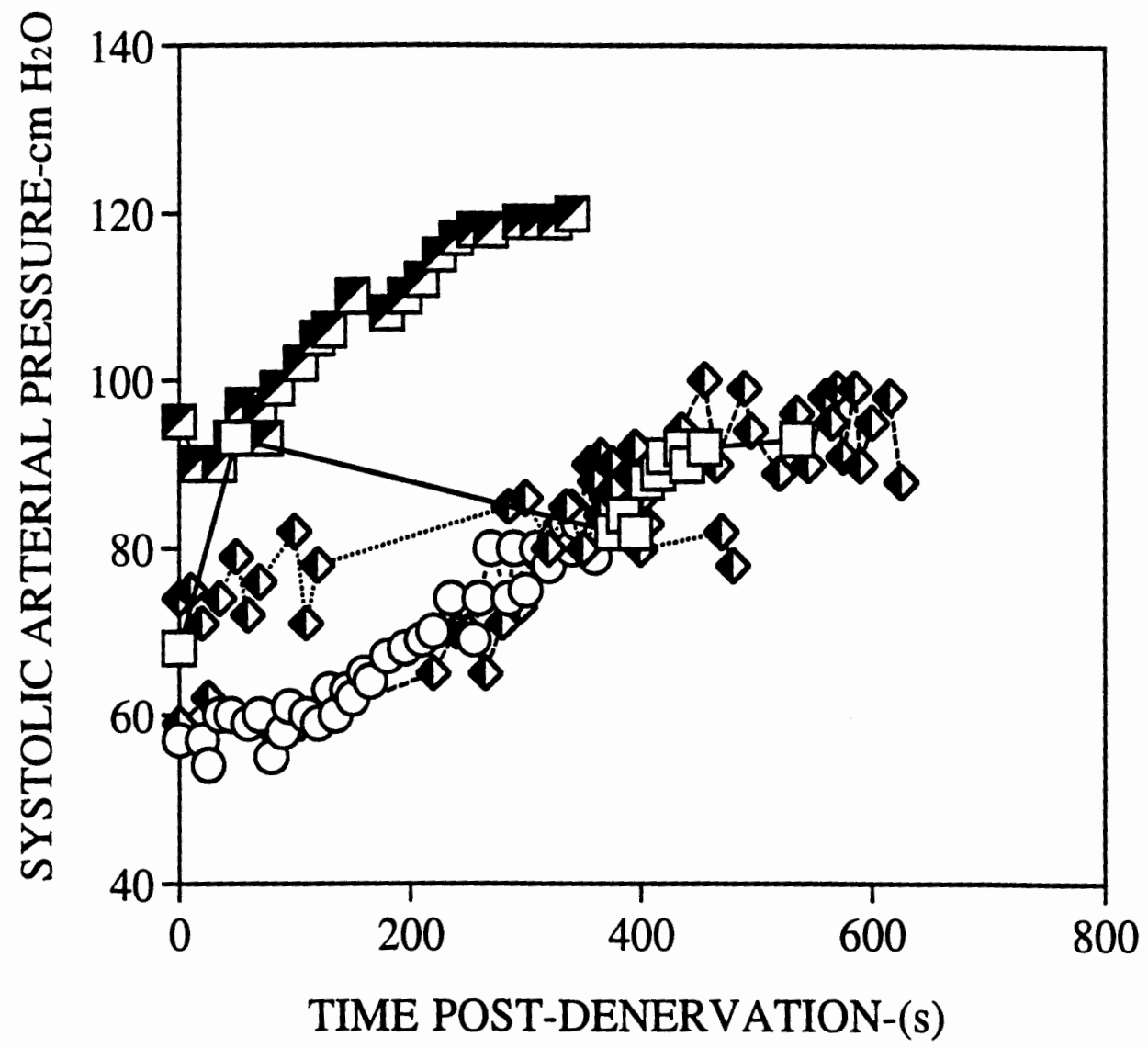

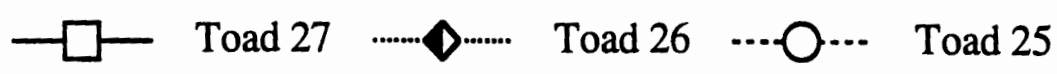

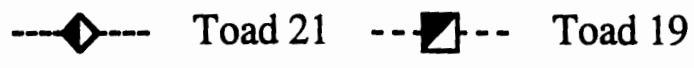

Figure 1. Effects of denervation on systolic arterial pressure. 


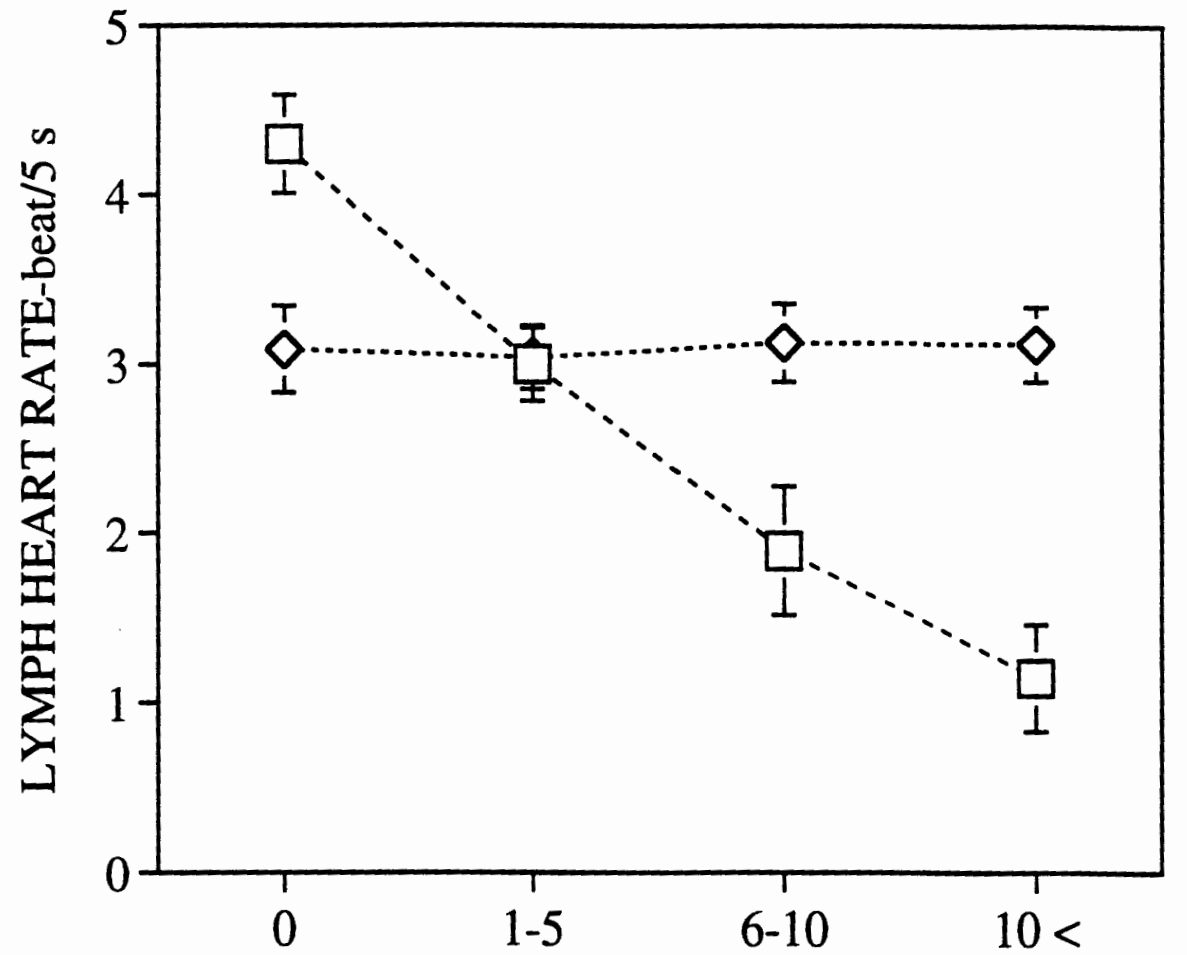

INCREASE IN PEAK SYSTOLIC PRESSURE-cm $\mathrm{H}_{2} \mathrm{O}$

$$
\begin{array}{ll}
\cdots \square \cdots & \text { Intact LHR } \\
\cdots \diamond \cdots & \text { Denervation LHR }
\end{array}
$$

Figure 2. Mean LHR due to natural increase in arterial pressure before and after denervation. 


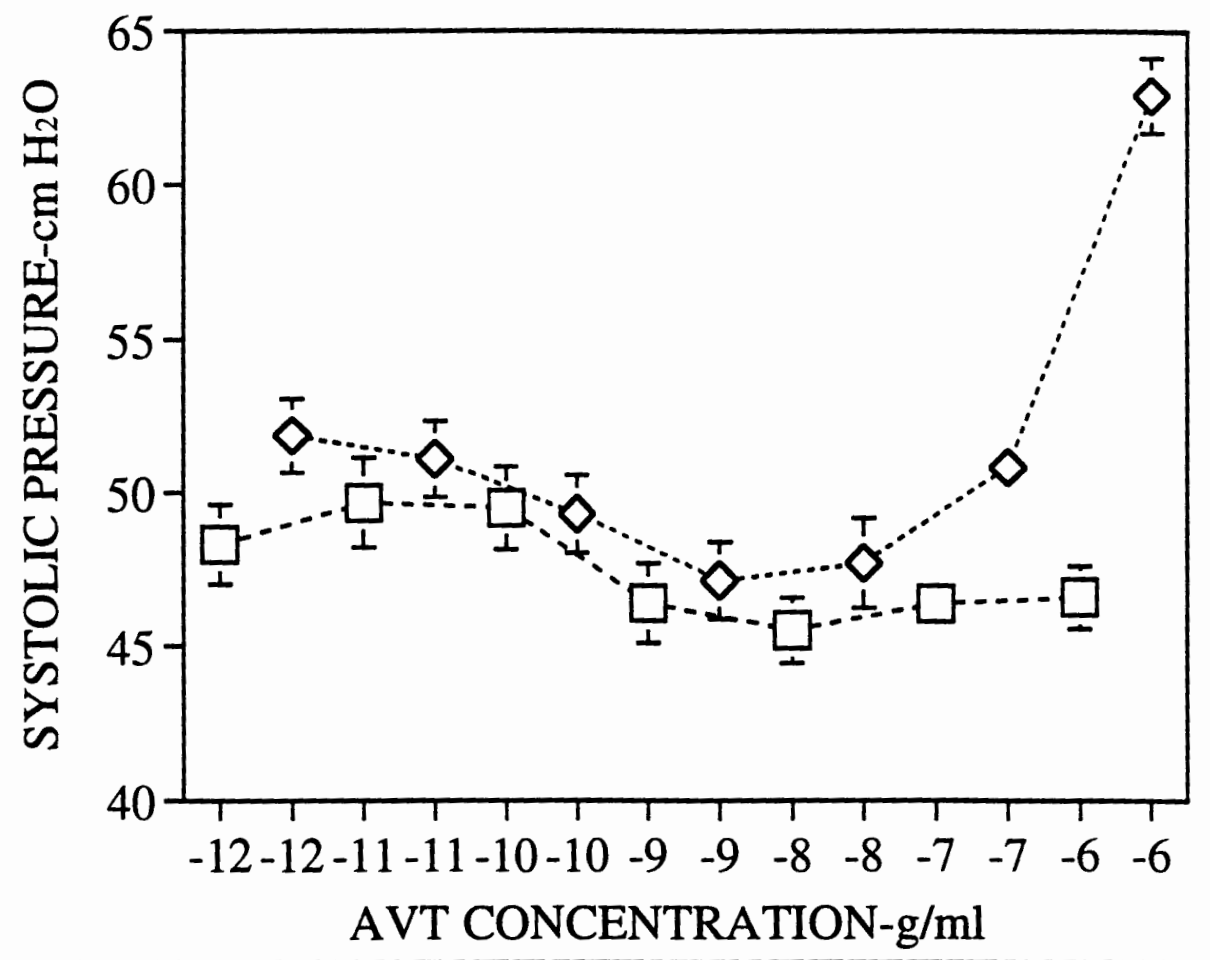

-- $\square$-- Mean Control Systolic ‥๑ - AVT Mean Systolic

Figure 3. Mean systolic arterial pressure due to increasing concentrations of arginine vasotocin. 


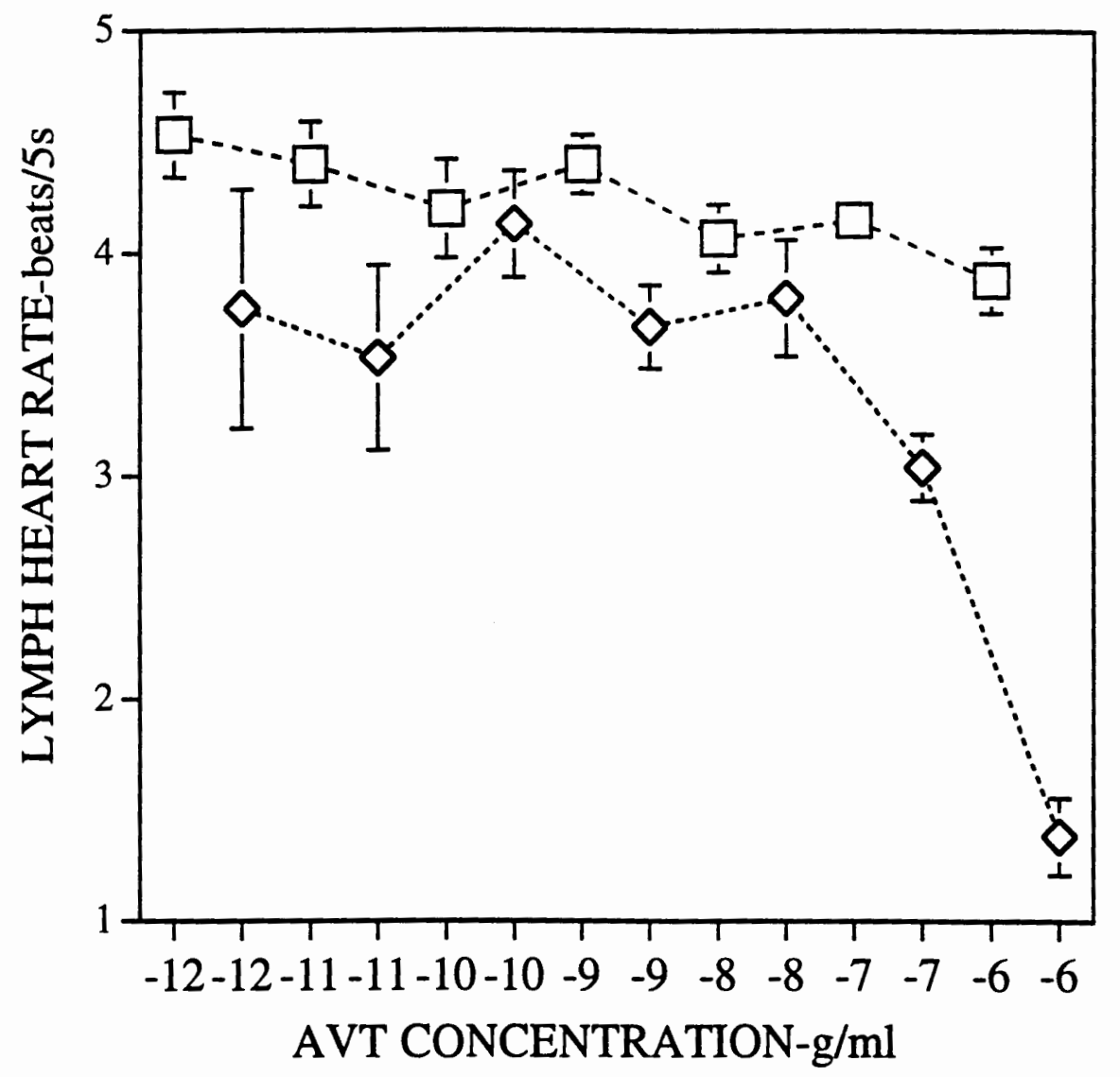

-- $\square--\quad$ Control Mean LHR $\cdots \diamond \cdots \quad$ AVT Mean LHR

Figure 4. Mean LHR due to increasing concentrations of arginine vasotocin. 
the mass of the animal used $(p>.05)$ and there was no significant effect $(p>.05)$ on systolic pressure due to mass of the animal.

Effect of increasing systolic pressure on LHR

Simple linear regression indicated a significant $(p<.05)$ negative correlation existed between increasing systolic blood pressure and lymphatic heart rate, with $\mathrm{r}^{2}=$ .394 over 381 cases for 5 animals. Increases in systolic blood pressure caused by administration of AVT at concentrations of $10^{-7} \mathrm{~g} / \mathrm{ml}$ showed no significant correlation with LHR when toads were analyzed for effects together. When analyzed individually, toads 8,9 and 14 illustrated a significant negative correlation between an increase in systolic blood pressure and LHR, toads 6 and 12 exhibited no correlation (TABLE II).

TABLE II

THE CORRELATION BETWEEN LYMPH HEART RATE

AND CHANGE IN SYSTOLIC PRESSURE

DUE TO AVT $10^{-7} \mathrm{~g} / \mathrm{ml}$

$\begin{array}{ccc}\text { TOAD } & \mathrm{r}^{2} & \mathrm{P} \\ 6 & .08 & .19 \\ 8 & .57 & <.05 \\ 9 & .27 & <.05 \\ 12 & .149 & .10 \\ 14 & .71 & <.05\end{array}$


Increases in systolic blood pressure due to AVT at a concentration of $10^{-6} \mathrm{~g} / \mathrm{ml}$ illustrated a significant negative correlation to change in LHR when analyzed as group effects, with $\mathrm{p}<.05$ and $\mathrm{r}^{2}=.544$. There was a significant negative correlation between increasing systolic pressure and LHR in all individual animals at this concentration of AVT (TABLE III).

\section{TABLE III}

THE CORRELATION BETWEEN INCREASING SYSTOLIC BLOOD PRESSURE AND LYMPH HEART RATE DUE TO AVT $10^{-6} \mathrm{~g} / \mathrm{ml}$

$\begin{array}{ccc}\text { TOAD } & \mathrm{r}^{2} & \mathrm{P} \\ 6 & .69 & <.05 \\ 8 & .59 & <.05 \\ 9 & .85 & <.05 \\ 12 & .66 & <.05 \\ 14 & .49 & <.05\end{array}$

Effects of change in mean systolic pressure on mean lymphatic heart rate were analyzed at arginine vasotocin (AVT) concentrations of $10^{-8} \mathrm{~g} / \mathrm{ml}, 10^{-7} \mathrm{~g} / \mathrm{ml}$, and $10^{-6}$ $\mathrm{g} / \mathrm{ml}$ (Figure 5). No significant differences from control in mean lymph heart rate were illustrated due to change in mean systolic pressure after administrations of AVT at concentrations of $10^{-8} \mathrm{~g} / \mathrm{ml}$. This was not the case during the administrations of either concentrations of $10^{-7} \mathrm{~g} / \mathrm{ml}$ or $10^{-6} \mathrm{~g} / \mathrm{ml}$ when systolic pressure increased.

Bilateral denervation of the rLN had a significant effect $(\mathrm{p}<.05)$ on systolic blood pressure (Figure 5). Administration of AVT at concentrations of $10^{-7} \mathrm{~g} / \mathrm{ml}$ 


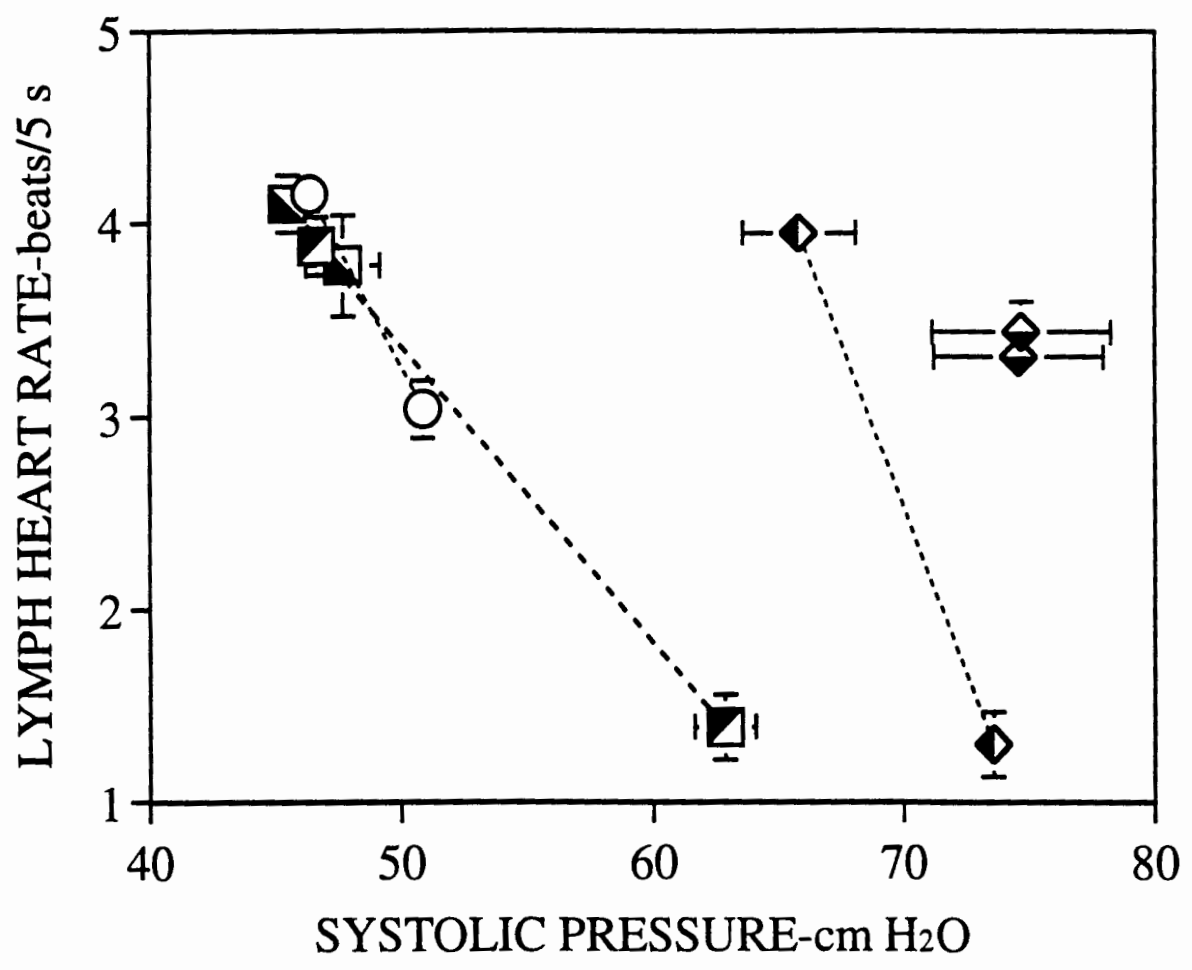

\begin{tabular}{|c|c|c|}
\hline$-\bullet-\quad$ AVT $10-6$ & $\cdots \diamond \cdots$ & Denervation at AVT 10-6 \\
\hline$\cdots \bigcirc \cdots \quad$ AVT $10-7$ & $\cdots \diamond \cdots$ & Denervation at AVT 10-7 \\
\hline
\end{tabular}

Figure 5. Control mean LHR and mean LHR due to increasing arterial pressure induced by arginine vasotocin before and after denervation. 
failed to have an effect on systolic pressure ( $p>.05$ ) post-denervation (Figure 5). AVT injections of $10^{-6} \mathrm{~g} / \mathrm{ml}$ induced a significant increase in systolic pressure $(\mathrm{p}<$ .05 ) in the three animals which were injected post-denervation (Figure 5).

Additionally, increased systolic pressure due to this hormone concentration caused a significant decrease $(\mathrm{p}<.05)$ in lymph heart rate. AVT $10^{-7} \mathrm{~g} / \mathrm{ml}$ failed to exhibit any effect of lymphatic heart rate.

\section{Effects due to angiotensin II}

ANG II increased systolic blood pressure from control values $(\mathrm{p}<.05)$ at concentrations of $10^{-6} \mathrm{~g} / \mathrm{ml}, 10^{-5} \mathrm{~g} / \mathrm{ml}$, and $10^{-4} \mathrm{~g} / \mathrm{ml}$ (Figure 6$)$. These concentrations led to significant decreases $(p<.05)$ in lymphatic heart rate (Figure 7). Increasing systolic blood pressure was inversely correlated to lymphatic heart rate in three of the test animals for concentrations of $10^{-6} \mathrm{~g} / \mathrm{ml}$ and $10^{-5} \mathrm{~g} / \mathrm{ml}$ and three of four at a concentration of $10^{-4} \mathrm{~g} / \mathrm{ml}$. Increase in mean systolic blood pressure, due to the three concentrations of ANG II mentioned, induced a drop in mean lymphatic heart rate from control rates (Figure 8).

\section{Effects of direct stimulation}

Direct unilateral stimulation of the recurrent laryngeal nerve achieved two results. One result was the reduction of lymphatic heart rate which was clear in all five animals. The voltage necessary to induce reduction in heart rate ranged from 1.6 to $6.0 \mathrm{~V}$. Initiation of unilateral stimulation also induced cessation of posterior lymph heart contraction (Figure 9), that were significantly different from the normal rates of 3 to 6 beats per $5 \mathrm{~s}$ monitored in the $60 \mathrm{~s}$ before stimulation. Once contraction was halted, elapsed time before lymph heart rate returned to normal in each animal ranged 


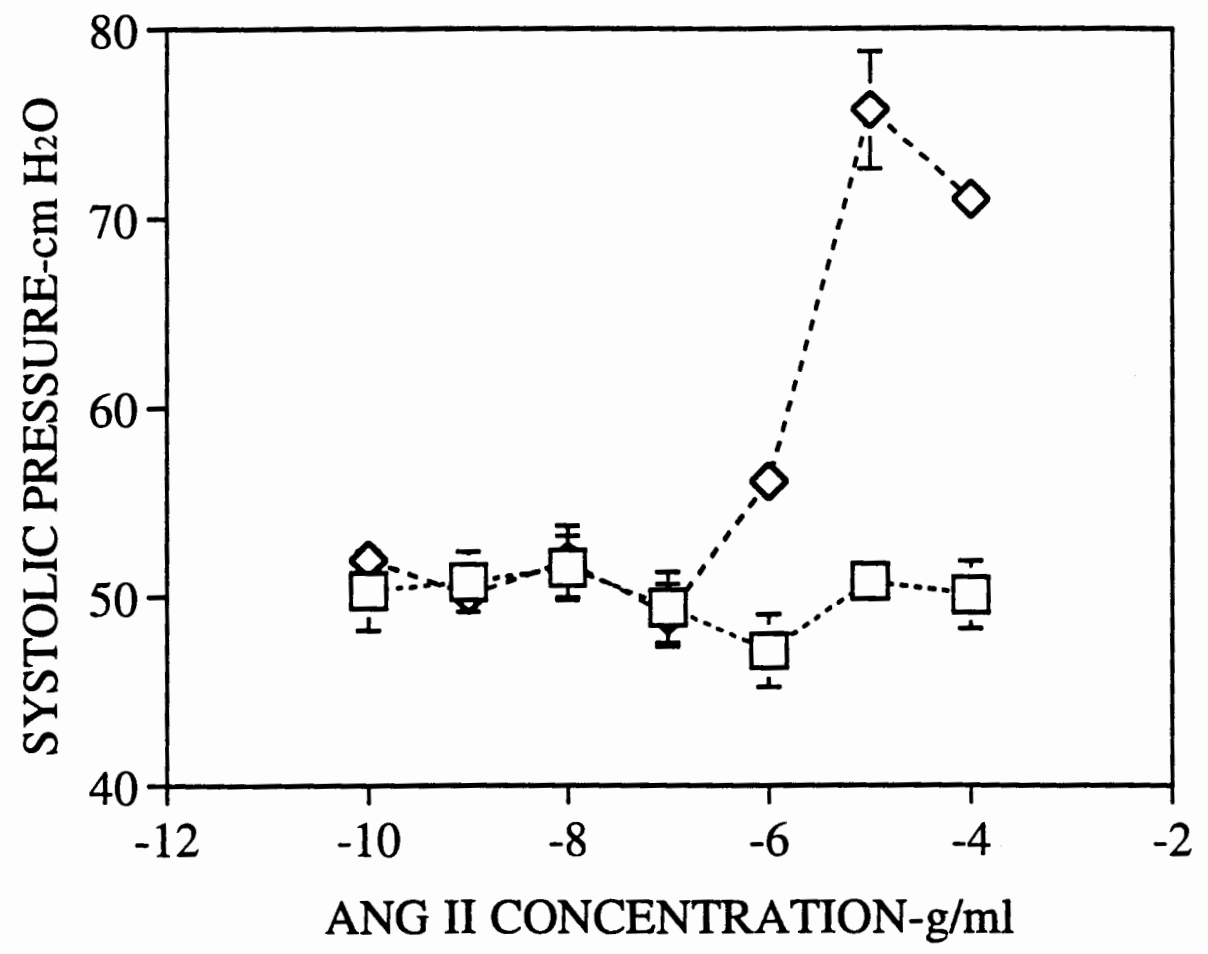

$\cdots \square$-..- Control Mean Systolic $\cdots \diamond-\cdot \quad$ ANG II Mean Systolic

Figure 6. Effects of increasing concentrations of angiotensin II on mean systolic arterial pressure. 


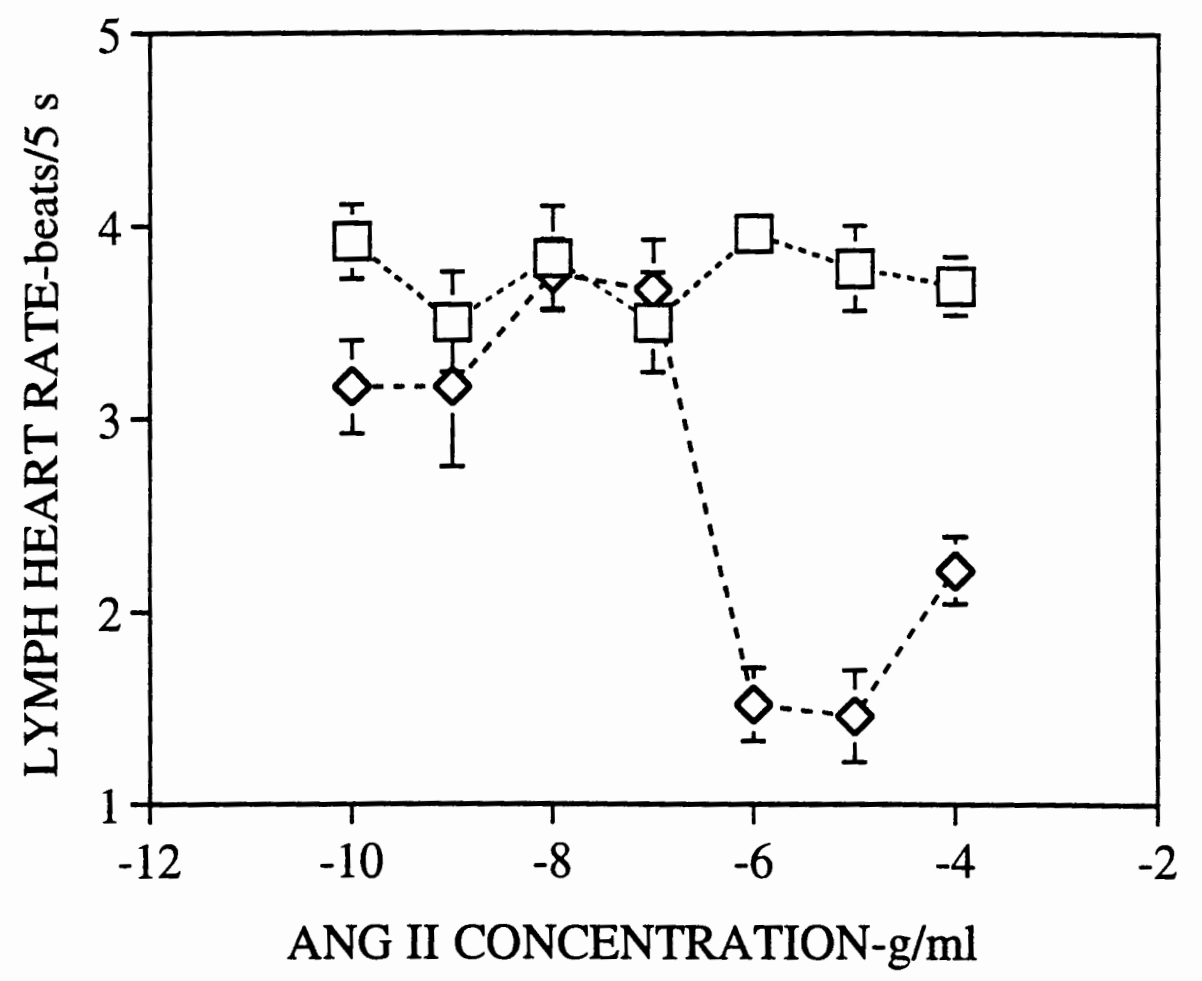

‥ $\square \cdots \quad$ Mean LHR Control $\cdots \diamond \cdots \quad$ ANG II Mean LHR

Figure 7. Effects of increasing concentrations of angiotensin $\|$ on mean LHR. 


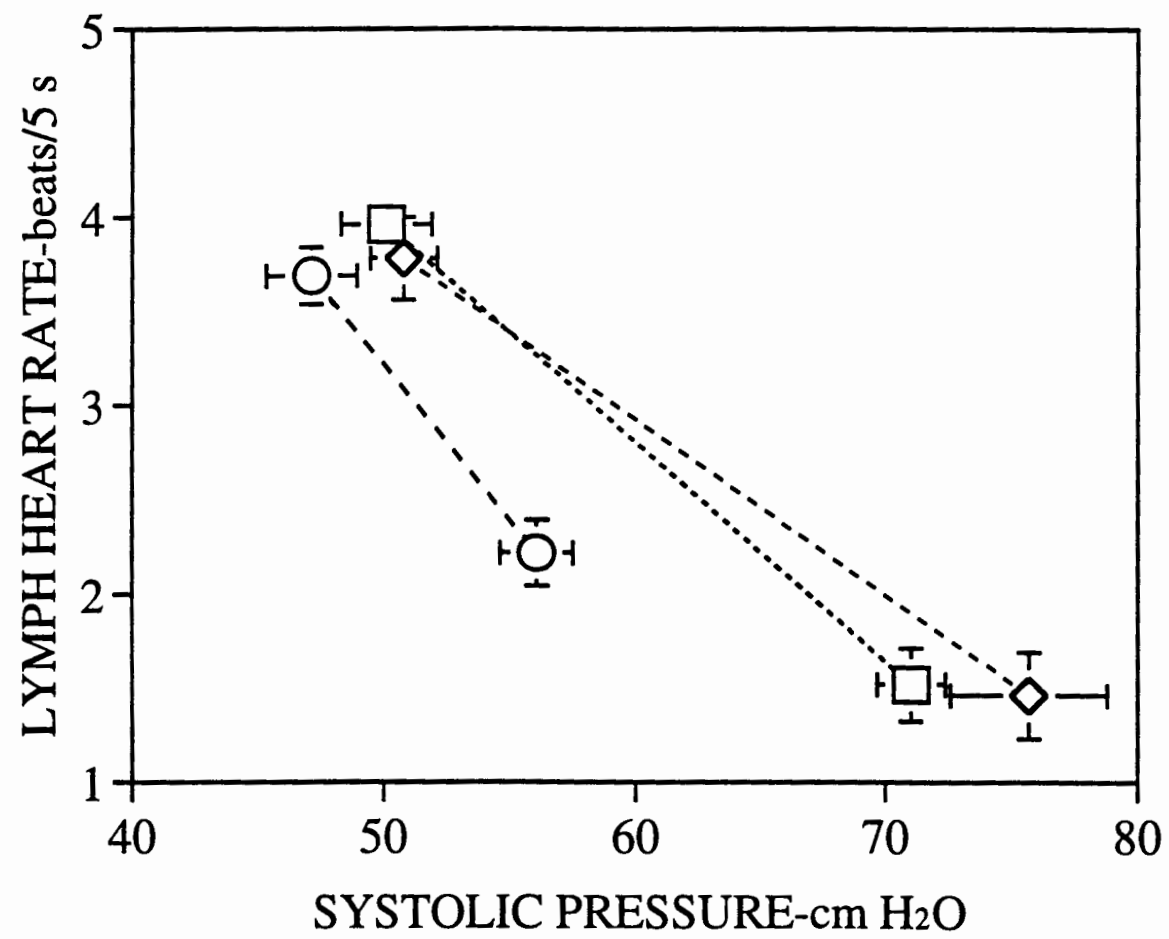

$\cdots \square \cdots \quad$ LHR at Angiotensin 10-6

-- $\diamond--$ LHR at Angiotensin 10-5

- -O- LHR at Angiotensin 10-4

Figure 8. Control mean LHR and mean LHR due to increases in arterial pressure induced by angiotensin 11 . 


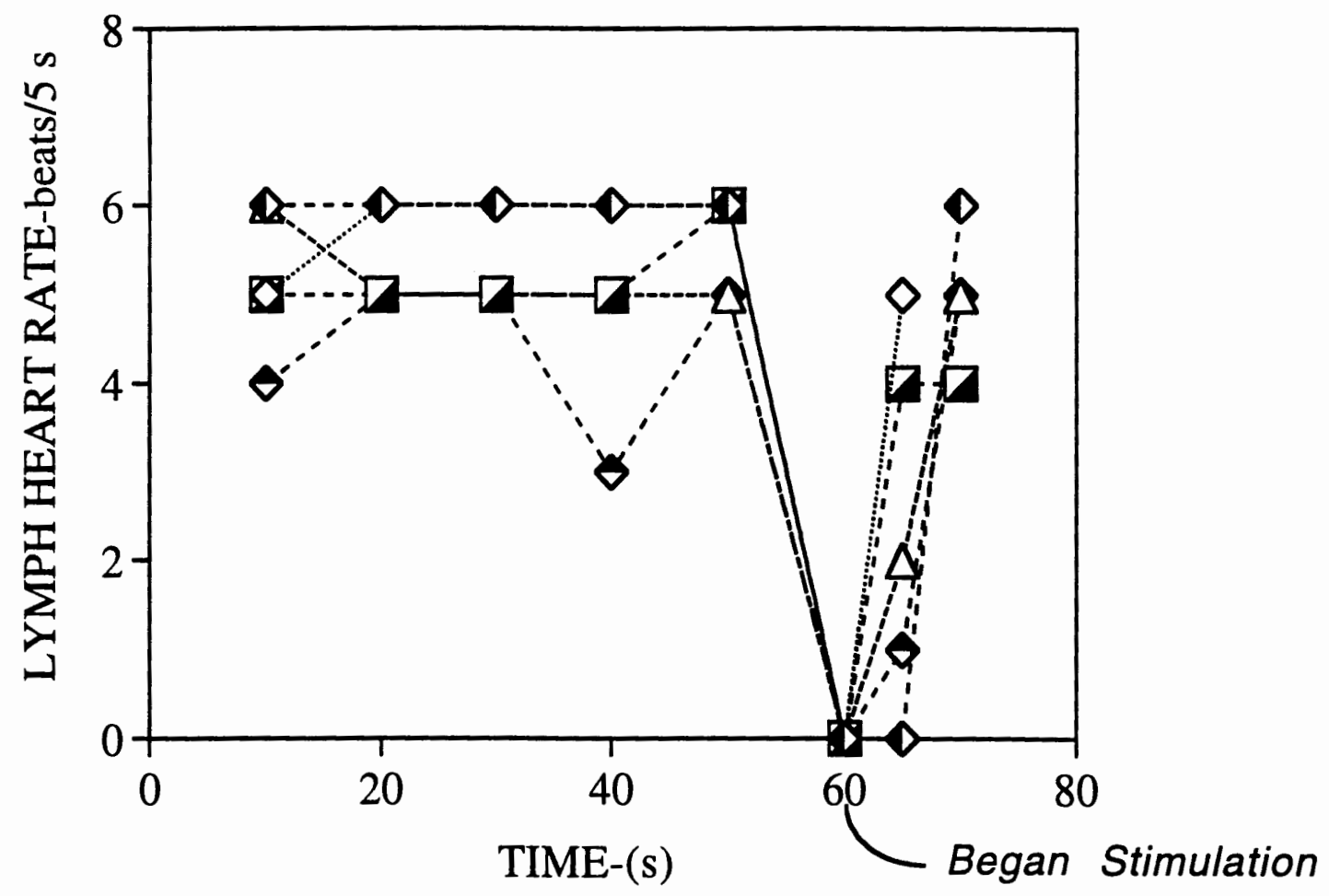

$\cdots$ -

$\cdots-\cdots$ Toad $33 \quad \cdots \diamond \cdots$ Toad 34

Figure 9. LHR 60 seconds before and during stimulation of the recurrent laryngeal nerve. 
from 5 to $20 \mathrm{~s}$. The second result was a decrease in systemic blood pressure of 0 to 5 $\mathrm{cm}$ of water during the stimulation period. Therefore, the reduction in LHR was not a consequence of an increase in arterial pressure. 


\section{DISCUSSION}

All data from the present study support the existence of a negative feedback loop between increasing arterial pressure and lymphatic heart rate. This feedback loop utilizes baroreceptors located in the pulmocutaneous artery to decrease lymphatic heart rate during periods of increase in arterial pressure. Increases in arterial pressure via natural variation or hormone administration caused a reduction in lymphatic heart rate. Denervation of the

rLN eliminated lymphatic heart response to elevation of arterial pressure. Direct stimulation to the rLN stopped lymph heart contraction without increasing arterial pressure, illustrating its role in the negative feedback control loop.

Hormone administration illustrated significant pharmacological effects on the lymphatic and the cardiovascular systems. Arginine vasotocin exhibited pressor effects on the cardiovascular system at concentrations $10^{-6} \mathrm{~g} / \mathrm{ml}$ and $10^{-7} \mathrm{~g} / \mathrm{ml}$ which was in agreement with the data of Wilson et al. (1986). Wilson et al. (1986) found upon infusion of these concentrations an initial depressor effect on systolic pressure followed by a pressor effect. No depressor effect was recorded in the current data due to either concentrations, and the reasons for this discrepancy are unclear. Pressor effects elicited via injections of ANG II $10^{-6} \mathrm{~g} / \mathrm{ml}$ were similar to those found in prior studies (Wilson et al. 1986). The present study indicated that maximal vasoconstriction was achieved with injections of ANG II $10^{-5} \mathrm{~g} / \mathrm{ml}$, which prior studies failed to utilize. Lymphatic heart rate response to hormone infusion was due to increases in systolic blood pressure.

Administrations of AVT $10^{-7} \mathrm{~g} / \mathrm{ml}$ failed to reduce the rate of contraction in 2 animals due to peak arterial pressure being achieved below threshold pressure. 
Baroreceptors located in the PCA are recruited once systolic pressure reaches a threshold level. As pressure approaches threshold, discharge frequency in the PCA baroreceptors increase as supported by artificial distention studies (Van Vliet and West 1987). The correlation between increasing arterial pressure and reduction of LHR is further indicated when effects of infusion of AVT $10^{-7} \mathrm{~g} / \mathrm{ml}$ are analyzed in concert with effects due to AVT $10^{-6} \mathrm{~g} / \mathrm{ml}$. Those animals in which LHR was not affected by increased arterial pressure at AVT $10^{-7} \mathrm{~g} / \mathrm{ml}$ experienced pressures 6 to 28 $\mathrm{cm}$ of water pressure below those achieved at AVT $10^{-6} \mathrm{~g} / \mathrm{ml}$. Pressure stimulation due to the higher AVT concentration reached threshold of PCA baroreceptors and reduced LHR to zero. Infusions of ANG II reduced LHR to zero at concentrations of $10^{-6} \mathrm{~g} / \mathrm{ml}$ and $10^{-5} \mathrm{~g} / \mathrm{ml}$. In each case the arterial pressures achieved were equal to or greater than those achieved with injections of AVT at a concentration $10^{-6} \mathrm{~g} / \mathrm{ml}$ insuring threshold pressure was exceeded. The significant reduction in LHR due to elevated arterial pressure supports the concept of control of lymphatic heart activity via negative feedback control from PCA baroreceptors. The significance of PCA baroreceptors is further indicated via denervation and direct stimulation of the rLN which innervates these structures.

Bilateral denervation of the rLN induced a transient acute rise in systolic pressure in resting conscious Bufo marinus. Systolic pressure continued to rise post denervation while exhibiting an oscillatory pressure wave. The sinusoidal wave pattern is in agreement with previous data (Van Vliet and West 1989) and indicates a positive removal of the rLN. However, arterial pressure failed to decline to control resting levels. This differs from the results found in a similar study by Van Vliet and West (1989) in which pressure returned to control levels. The time course of this study was shorter and may not have allowed the establishment of a true resting 
pressure given that measurements were taken less than 1 hour post-denervation (Van Vliet and West 1989). Restoration of resting arterial blood pressure following denervation was partially attributed, by Van Vliet and West, to renal and/or endocrine mechanisms which may adjust fluid volume, independent of arterial baroreceptors (1989). However, an additional mechanism could involve an adjustment of central integration, utilizing available baroreceptors in the system, once denervation of the pulmocutaneous artery baroreceptors was achieved (Van Vliet and West 1989). Since innervation of baroreceptors located in the aortic arches (Ishii, Ishii, and Kusakabe 1985) and carotid labyrinth (Ishii, Honda, and Ishii 1966) remained intact during the study, control of pressure variation may have been assumed by one of these remaining baroreceptor sites implicated by Van Vliet and West (1989). The lymphatic heart control mechanism was eliminated, in addition to cardiovascular control mechanism, with the denervation of the rLN. Natural increase in pre-denervation systolic pressure reduced lymphatic heart rate, however post-denervation increases failed to elicit a similar drop in LHR with elevation of systolic blood pressure. Removal of PCA baroreceptors from the control loop accounted for the continuation of lymph heart activity as systolic blood pressure increased. Further data supporting the impact of denervation on lymph heart rate is indicated in the time difference between peak systolic pressure achieved and return of normal lymphatic heart rate. Lymph heart rate returned to control values prior to the arterial system reaching maximum systolic pressure. Cessation of lymph heart contraction due to vasoconstriction caused by post-denervation AVT infusion infers that baroreceptors located in either the branches of the aorta (Ishii, Ishii, and Kusakabe 1985) or the carotid body (Ishii, Honda, and Ishii 1966) assume the role of feedback as is the case in cardiovascular control (Van 
Vliet and West 1989). Thus denervation of PCA baroreceptors had a transient elimination of cardiovascular control and lymphatic heart control.

Direct stimulation of the rLN reduced lymph heart contraction to zero upon initiation of the stimulus. Intensity, duration, and frequency of the stimulation used were similar to those in previous studies of cardiovascular responses (Van Vliet and West 1986); however, a change in mean arterial pressure was the only cardiovascular variable analyzed in this study. Failure of mean arterial pressure to increase, and during some stimulus periods decrease, indicates similar arterial pressure responses to those found prior to this study (Van Vliet and West 1986). Unilateral application of the stimulus, which was determined to have a weaker effect on cardiovascular response, could explain return of LHR to control rates before stimulation was discontinued in some trials. Van Vliet and West indicated cardiovascular reactions to bilateral stimulation were more effective at reducing arterial blood pressure (1986). A similar reaction may have been elicited from the lymphatic hearts, with bilateral stimulation of the rLN inducing the hearts to stop for longer periods of time. Stimuli needed to stop lymph heart contraction was within the range utilized during prior studies to induce a low threshold depressor response of the cardiovascular system (Van Vliet and West 1986) in 4 of the 5 animals used. Thus, the possibilities of stimulus recruiting afferent fibers from the glottis or nociceptors are reduced. Given the results the recurrent laryngeal nerve is part of the negative feedback loop that controls LHR.

In Summary the goal of the study was to determine the role of baroreceptors innervated by the recurrent laryngeal nerve in control of lymph heart rate. Baroreceptors of the PCA serve to control lymphatic heart rate during periods of increased arterial pressure. The functional significance of these receptors is clear 
when considering the amount of fluid volume lymphatic hearts can return to the cardiovascular system. Baroreceptors located in the PCA reduce LHR during periods of elevated arterial pressure in an effort to limit potentially damaging increases in hydrostatic pressure in the lungs. Studies of direct hormonal effects on lymphatic heart function should consider the pressor effects on the cardiovascular system and the reduction in lymphatic heart function due to pressor effect. 


\section{LITERATURE CITED}

Baustian, M. 1988. The contribution of lymphatic pathways during recovery from hemorrhage in the toad Bufo marinus. Physiological Zoology 61(6):555-563.

Beddard, F. E. 1908. On the musculature and other points in the anatomy of the engystomatid frog, Breviceps verrucosus. Proceeding of the Zoological Society of London. In O. F. Kampmeier, ed 1969. Evolution and comparative morphology of the lymphatic system. Thomas, Springfield, Ill.

Bentley, P. J. 1974. Actions of neurohypophyseal peptides in amphibians, reptiles, and birds. Handbook if Physiology Section 8 Endocrinology, Chapter 20:545-563.

DeGrauw, E. 1995. Personal communication.

Feder, M. E., and W. W. Burggren. ed. 1992. Environmental Physiology of the Amphibians. The University of Chicago Press, Chicago.

Guyton, A. C. 1991. Textbook of medical physiology 8th edition. W. B. Saunders Company. Philadelphia, PA.

Hillman, S. S. 1978. Some effects of dehydration on internal distributions of water and solutes in Xenopus laevis. Comparative Biochemistry Physiology 61:303-307.

Hillman, S. S. 1987. Dehydrational effects on cardiovascular and metabolic capacity in two amphibians. Physiological Zoology 60(5):608-613.

Hillman, S. S., A. Zygmunt, and M. Baustian 1986. Transcapillary fluid forces during dehydration in two amphibians. Physiological Zoology 60(3):339-345.

Hoffman, A., and M. B. Cordeiro De Sousa. 1982. Cardiovascular reflexes in conscious toads. Journal of Autonomic Nervous Systems 5:345-355.

Ishii, K., K. Honda, and K. Ishii. 1966. The function of the carotid labyrinth in the toad. Tohoku Journal of Experimental Medicine 88:103-116. 
Ishii, K., and K. Ishii. 1978. A reflexogenic area for controlling the blood pressure in toad (ㅂfo vulgaris formosa). Japanese Journal of Physiology 28:423-431.

Ishii, K., K. Ishii, and T. Kusakabe. 1985. Chemo- and baroreceptor innervation of the aortic trunk of the toad Bufo vulgaris. Respiration Physiology 60:365-375.

Jones, J. M., L. A. Wentzell, and D. P. Toews. 1992. Posterior lymph heart pressure and rate and lymph flow in the toad Bufo marinus in response to hydrated and dehydrated conditions. Journal of Experimental Biology 169:207-220.

Kampmeier, O. F. 1920. The development of the trunk and tail lymphatics and posterior lymph hearts in anuran embryos. Journal of Morphology and Physiology. 41:95-157.

Kampmeier, O. F. ed. 1969. Evolution and comparative morphology of the lymphatic system. Thomas, Springfield, Ill.

Meyer, F. 1927. Versuche uber blutdruckzugler beom frosch. Pflugers Archives 215:545-552. In M. E. Feder, and W. W. Burggren. ed. 1992. Environmental Physiology of the Amphibians. The University of Chicago Press, Chicago.

Morris, J. L. 1981. Structure and function of ciliated peritoneal funnels in the toad kidney (Bufo marinus). Cell Tissue Research. 217:599-610.

Mullen, T. L., and R. H. Alavardo. 1976. Osmotic and ionic regulation in amphibians. Physiological Zoology 49:11-23.

Muller, J. 1834. Ueder die Existenz von nier getrennten regelmassig pulsierenden Herzen, welche mit dem lymphatischen System in Verbinding stehen bei einigen Amphibien (frogs, toads, salamanders, lizards). Muller Archives of Anatomy and Physiology. In O. F. Kampmeier. ed. 1969. Evolution and comparative morphology of the lymphatic system. Thomas, Springfield, Ill. 
Neil, E., L. Strom, and Y. Zotterman. 1950. Action potential studies of afferent fibers in the IXth and Xth cranial nerves of the frog. Acta Physiologica Scandinavica $20: 338-350$.

Obara, S. 1962. Single unit activity and mechanogram of the coccygeal lymph heart of toad. Japanese Journal of Physiology. 12:161-175.

Panizza, B. 1833. Sopra il sistema linfatico dei retilli. Ricerche zootomiche. Pavia. In O. F. Kampmeier. ed. 1969. Evolution and comparative morphology of the lymphatic system. Thomas, Springfield, Ill.

Parsons, G. G., L. A. Wentzell, J. M. Jones, and D. P. Toews. 1994. The role of arginine vasotocin in the control of posterior lymph heart function in the toad Bufo marinus (L.). Physiological Zoology 67(2):515-525.

Priestley, J. 1878. An account of the anatomy and physiology of batrachian lymphhearts. Journal of Physiology, London 1:1-17.

Radwanska, M. 1906. Die vorderen lymphherzen des frosches. Bulletin of the International Academy of Science, Cracov, pp. 213-228. In O. F. Kampmeier. ed. 1969. Evolution and comparative morphology of the lymphatic system. Thomas, Springfield, Ill.

Ranvier, L. 1890. De la membrane du sac lymphatique oesophagien de la grenoville. C R Academic Science of Paris. 111:863. In O. F. Kampmeier. ed. 1969. Evolution and comparative morphology of the lymphatic system. Thomas, Springfield, Ill.

Rugh, R. 1938. Structure and function of peritoneal funnels of the frog, Rana pipiens. Proceedings of the Society of Experimental Biological Medicine. 37:717-727.

Ruibal, R. 1962. The adaptive value of bladder water in the toad, Bufo cognatus. Physiological Zoology 35:218-223. 
Shoemaker, V. H. 1964. The effects of dehydration on electrolyte concentration in a t oad, Bufo marinus. Comparative Biochemistry Physiology 13:261-271.

Shoemaker, V. H., and K. Nagy. 1977. Osmoregulation in amphibians and reptiles. Annual Review of Physiology 39:449-471.

Smits, A. W., N. H. West, and W. W. Burggren. 1986. Pulmonary fluid balance following pulmocutaneous baroreceptor denervation in the toad. Journal of Applied Physiology 61:331-337.

Talbot, C. R. 1993. Amphibian skin and its role in the physiological transport of gases and ions. $\mathrm{Ph}$. D. dissertation. The University of Chicago. pp. 146.

Van Vliet, B. N., and N. H. West. 1985. Multiple cardiorespiratory afferents within the recurrent laryngeal nerve of the toad, Bufo marinus. In : Gilles, R. Ed. Comparative Physiology and Biochemisrty. First Congr. Int. Union Biol. Sci. Leige. Belgium, p A59.

Van Vliet, B. N., and N. H. West. 1986. Cardiovascular responses to electrical stimulation of the recurrent laryngeal nerve in conscious toads (Bufo marinus) Journal of Comparative Physiology B 156:363-375.

Van Vliet, B. N., and N. H. West. 1987. Responses to circulatory pressures, and conduction velocity, of pulmocutaneous baroreceptors. Journal of Physiology $388: 41-53$

Van Vliet, B. N., and N. H. West. 1987. Response characteristics of pulmocutaneous arterial baroreceptors in the toad, Bufo marinus. Journal of Physiology 388:55-70.

Van Vliet, B. N., and N. H. West. 1989. Cardiovascular responses to denervation of pulmocutaneous baroreceptors in toads. American Journal of Physiology 256:R946-R954. 
Van Vliet, B. N., and N. H. West. 1994. Phylogenetic trends in the baroreceptor control of arterial blood pressure. Physiological Zoology. 67(6):1284-1304.

Wentzell, L. A., S. A. McNeil, and D. P. Toews. 1993. The role of the lymphatic system in water balance processes in the toad, $\underline{\text { Bufo marinus. Physiological }}$ Zoology. 66(3):307-321.

West, N. H., and B. N. Van Vliet. 1983. Open-loop analysis of the pulmocutaneous baroreflex in the toad Bufo marinus. American Journal of Physiology 245:R642-R650.

Wilson, J. X., K. J. Saleh, E. D. Armogan, and E. J. Jaworska. 1986. Catecholamine and blood pressure regulation by gonadotropin-releasing hormone analogs in amphibians. Canadian Journal of Physiology and Pharmacalogy 65:2379-2385.

Withers, P. 1992. Comparative Animal Physiology. Saunders College Publishing.

Zwemer, R. L., and V. G. Fogia. 1943 Fatal loss of plasma volume after lymph heart destruction in toads. Proceedings of the Society for Experimental Biology and Medicine 53:14-17. 